\title{
THE ONSET OF STUTTERING FOLLOWING DRUG OVERDOSE
}

\author{
GARY J. RENTSCHLER, LYNN E. DRIVER, and \\ ELIZABETH A. CALLAWAY \\ The University of Michigan \\ Ann Arbor, Michigan
}

\begin{abstract}
Recently, some attention has been focused on acquired stuttering, disfluencies that begin in adulthood. The nature of acquired stuttering differs in several respects from developmental stuttering. A case of acquired stuttering following drug overdose is presented and contrasted with previously reported cases. The case is noteworthy in that, while many characteristics of acquired stuttering are evidenced, several symptoms associated with developmental stuttering are also observed. The findings are discussed in terms of a possible link between developmental and acquired forms of stuttering.
\end{abstract}

\section{INTRODUCTION}

Many researchers suggest it is likely that there are multiple etiologies of stuttering and that stutterers do not represent a homogeneous population. Some have proposed different types of stutterers (Van Riper, 1971; Riley and Riley, 1980). However, these groupings are not always easily distinguished, and there is lack of agreement on the delineations. Consequently, there has not been a universally adopted system of classification. One subgroup of stutterers, however, is distinguished with relative ease: those whose disfluencies begin in adulthood, generally referred to as "acquired stutterers." It is the intent of this paper to survey the literature on acquired stuttering, provide a review of selected drugs that interrupt speech fluency, and present a case report of acquired stuttering whose characteristics differ markedly from previous case reports.

A body of case reports and studies on acquired stuttering is beginning to amass. Close examination of the literature addressing acquired stuttering reveals considerable overlap and inconsistency in terminology; neurologic stuttering, acquired stuttering, neurologic stammering, neurogenic stuttering, and cortical stuttering represent a few of the most frequently used terms. Subclassifications within these categories further complicate comparisons across studies. Comparison of carefully documented case studies is essential at this level of our understanding of the disorder.

Address correspondence to Gary J. Rentschler, Ph.D., University of Michigan, $1111 \mathrm{E}$. Catherine St., Ann Arbor. MI 48109-2054. 
Before reviewing the characteristics of acquired stuttering, the terms listed herein will be examined in an attempt to clarify their meaning and usage. "Acquired stuttering" is perhaps the most general term, referring to stuttering that follows cerebral lesions of traumatic or vascular etiology involving the left hemisphere (Mazzucchi et al., 1981). Mazzucchi et al. categorized acquired stuttering into three subtypes as follows:

1. Stuttering associated with signs of language impairment (aphasia)

2. Isolated stuttering: stuttering not associated with language impairment or neuropsychologic abnormalities

3. Preexistent mild stuttering: marked worsening of preexistent developmental stuttering following neurologic damage

Quinn and Andrews (1977) use "neurological stuttering," to refer to two forms of acquired stuttering associated with neurologic pathology. The investigators suggest "that stuttering may be a presenting symptom of progressive neurological disease . . . [and] . . . that a speech disorder indistinguishable from common (developmental) stuttering may follow cerebral injury in adulthood" (p. 699).

"Neurological stammering" has been used to describe stuttering following severe closed head injury (Inglis, 1979). The patient had no premorbid history of speech disorder, and presented initial mild-moderate dysphasia following the accident.

Canter (1971) used the term "neurogenic stuttering" to refer to stuttering that results from CNS damage, and suggested threc subclasses, as follows:

1. Apraxic stuttering: stuttering as a result of damage to brain centers involved in motor programming

2. Dysarthric stuttering: stuttering as a result of faulty motor execution

3. Dysnomic stuttering: characterized by dysfluencies due to word lapses, as in aphasic syndromes

"Cortical stuttering" refers to stuttering "resulting from hemispheric, although not necessarily cortical, lesions in which deficits in bilaterally innervated brain mechanisms produce stuttering symptoms" (Rosenbek et al., 1978, p. 93).

Although most researchers are in agreement concerning stuttering behavior in the presence of neurologic damage, some additional factors serve to confound comparisons. For example, some include previously developmental stutterers as a subgroup (Mazzucchi et al., 1981), while they are excluded by others (Rosenfield, 1972); still others fail to address the issue at all. Some researchers underscore the importance of distinguishing acquired stuttering concomitant with language impairment from isolated acquired stuttering (Mazzucchi et al., 1981); others (Canter, 1971) do not make a distinction. Motor problems associated with neurologic 
impairment, dysarthria, and apraxia (Canter, 1971) represent an added factor.

It is evident that neurologic damage that affects speech may result in many forms of impairments. In attempting to synthesize the literature, four distinctions appear to represent significant delineations of acquired stuttering in terms of effecting disfluencies:

i. Stuttering concomitant with language impairment: impaired language and word-finding abilities associated with aphasia and neurologic impairment that affect the fluency of speech

2. Stuttering associated with motor speech impairment-the results of damage to motor programming centers of the brain or the inability to execute speech patterns;

3. Recurrence of stuttering in individuals having experienced recovery from developmental stuttering;

4. Isolated acquired stuttering-individuals experiencing disfluencies in the absence of language or motor impairment, who never previously stuttered.

\section{CHARACTERISTICS OF ACQUIRED STUTTERING}

In order to generate a list of characteristic behaviors of acquired stuttering, it is necessary to identify the behaviors that pertain to each definition of the disorder. Table 1 displays the characteristics of acquired stuttering along the following dimensions:

1. Speech behaviors: features of speech identified in the literature as characterizing acquired stuttering; the presence or absence of each characteristic from reports in the literature is indicated by $(+)$ for the presence of the behavior and by $(-)$ for the absence of the behavior in the subjects observed. Those behaviors specifically cited as characteristic of isolated stuttering are entered with $(++)$ or $(--)$. No entry indicates that no mention of the item was made in the study.

2. Speech alterations: procedural or speaking conditions reported in the literature (e.g., delayed auditory feedback, miming). Case reports were examined for the presence or absence of these alterations, and a similar sign system was employed.

Examination of Table 1 indicates that many characteristics are observed overall, yet no single behavior is noted in every study, nor does any single study evidence every behavior. The result is a somewhat sketchy picture of the speech behaviors of acquired stuttering.

Looking specifically at features associated with cases of isolated stuttering, it appears that each feature listed has been observed in at least 


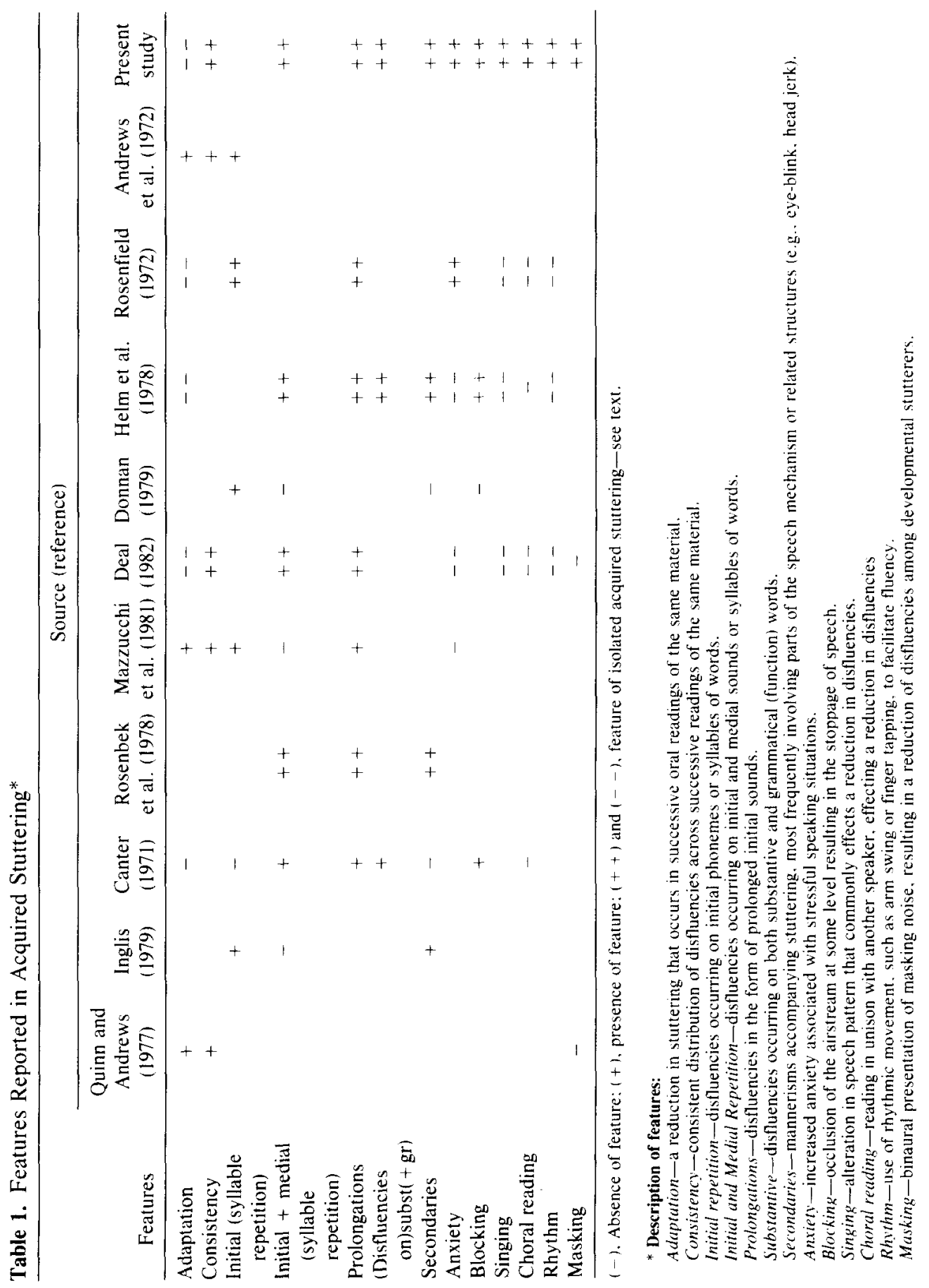


one of the studies. When examining the features found in three or more studies, the following characteristics emerge: (a) absence of the adaptation effect; (b) initial and medial syllable repetition; (c) prolongations; (d) presence of secondaries; (e) lack of improvement in singing; and (f) lack of improvement in choral reading. It is difficult to characterize the subgroup of isolated acquired stuttering due to inconsistency of features examined across studies. In addition, features that have been examined are difficult to compare because various subgroups of acquired stuttering have been combined in several studies.

Several cases of acquired stuttering secondary to brain damage have been reported in the literature (Arend, Handzel, and Weiss, 1962; Jones, 1966; Borkowski, Benton, and Spreen, 1967; Canter, 1971; Caplan, 1972; Rosenfield, 1972; Faimer, 1975; Helm, Butler, and Benson, 1978; Rosenbek et al., 1978; Donnan, 1979; Rosenfield, Miller, and Feltovich, 1980). Most reports indicated stuttering to be concurrent with language impairment.

Helm et al. (1978) summarized five features that characterized their patients:

1. Absence of the adaptation effect

2. Repetitions, prolongation, and blocks not restricted to initial syllables

3. Disfluencies on small grammatical words, as well as substantive words

4. Speaker does not appear to be anxious

5. Secondary symptomatology rarely observed

Two additional features were noted by Canter (1971), whose patients exhibited particular difficulty with the phonemes $/ \mathrm{r} /, / 1 /$, and $/ \mathrm{h} /$, and were more disfluent in choral speaking than self-formulated speech. However, Helm et al. (1978) did not note these features to be characteristic of their patients.

Helm et al. (1980) report that the acquired stutterers they evaluated evidenced one or more of certain characteristics on their battery of neuropsychologic tests, including: (a) difficulty drawing three-dimensional figures; (b) difficulty copying block designs; (c) difficulty reproducing alternating sequential hand positions; (d) difficulty singing melodies; and (e) difficulty reproducing tapping patterns. The investigators further noted that "patients with persistent stuttering tended to have difficulty with all of the above tasks, [while] the patients with transient stuttering of vascular origin tended to have difficulty with only the first three tasks" (p. 277).

The sex ratio in developmental stuttering is generally accepted to be about $3: 1(\mathrm{M}: \mathrm{F})$ among school-age children, increasing to nearly $8: 1$ in adulthood (Bloodstein, 1981). This increase is largely explained by the higher percentage of females apparently recovering from their fluency 
Table 2. Sex Ratio in Acquired Stuttering

\begin{tabular}{lc}
\hline \multicolumn{1}{c}{ Source (reference) } & Males: Female \\
\hline Andrews et al. (1972) & $1: 0$ \\
Rosenfield (1972) & $0: 1$ \\
Quinn and Andrews (1977) & $2: 0$ \\
Helm et al. (1978) & $9: 1$ \\
Rosenbek et al. (1978) & $7: 0$ \\
Mazzucchi et al. (1981) & $15: 1$ \\
Rosenfield et al. (1981) & $1: 0$ \\
Deal (1982) & $1: 0$ \\
Present study & $1: 0$ \\
Total & $37: 3$ \\
Ratio & $12.3: 1$ \\
\hline
\end{tabular}

${ }^{a}$ Reported from Veteran's Administration Hospital populations.

difficulties. Information regarding sex ratio and recovery in acquired stuttering is presented in Tables 2 and 3.

Table 2 displays the cumulative sex ratios reported in the literature. As is shown, the sex ratio in acquired stuttering appears to be about 12:1 (M:F). It should be noted that one possible source of error is that several studies were reported from Veterans Administration Hospital populations, representing a predominately male population.

In a review of a number of studies, Bloodstein (1981) reported that the percentage of developmental stutterers who experience recovery ranges from $36 \%$ to $79 \%$. Recovery among acquired stutterers (Table 3) appears to be less frequent. Information compiled from several case reports reveals that $29.4 \%(10 / 34)$ of acquired stutterers experience remission of their disfluencies. Helm et al. (1980) suggest that recovery (transient acquired stuttering) is associated with multifocal lesions in the left hemi-

Table 3. Recovery from Acquired Stuttering

\begin{tabular}{lcc}
\hline \multicolumn{1}{c}{ Source (reference) } & $\begin{array}{c}\text { Number of } \\
\text { cases } \\
\text { recovered }\end{array}$ & $\begin{array}{c}\text { Number of } \\
\text { cases } \\
\text { unresolved }\end{array}$ \\
\hline Andrews et al. (1972) & 0 & 1 \\
Rosenfield (1972) & 1 & 0 \\
Helm et al. (1978) & 2 & 8 \\
Rosenbek et al. (1978) & 2 & 5 \\
Mazzucchi et al. (1981) & 4 & 12 \\
Rosenfield et al. (1981) & 0 & 1 \\
Deal (1982) & 1 & 0 \\
Present study & 0 & 1 \\
Total: 38 & 10 & 28 \\
\hline
\end{tabular}


sphere (language dominant), while persistent stuttering is associated with bilateral neurologic damage (resulting from cerebral disease or trauma).

Some studies have had difficulty separating language impairment, dysarthria, and disfluency. Rosenfield's (1972) patient and two of Rosenbek et al.'s (1978) subjects stuttered in the absence of language impairment. Cases of acquired stuttering concomitant with language impairment, indeed, are complicated by the supposition that disrupted language may be intimately involved in the etiology of the disfluencies. Investigations of developmental stuttering suggest that some stutterers may have a language delay or disorder concomitant with their stuttering (Gregory and Hill, 1980; Riley and Riley, 1980). Certainly cases of acquired stuttering in the absence of language involvement present the opportunity to investigate the disorder with less likelihood of an interaction effect. However, the close association between cerebral injury and language impairment is well known. Some reported cases observed disfluencies after language impairment had subsided. Andrews, Quinn, and Sorby (1972) reported patients whose stuttering persisted at least 4 yr after aphasia had resolved.

\section{SELECTED DRUGS AFFECTING SPEECH}

Language and speech function often index the effects of a variety of disorders, including drug toxicity (Darby, 1981). Few investigations have systematically examined the effects of commonly used drugs on speech and language performance. Recent findings suggest that certain drugs may alter neurologic function affecting abnormal speech and/or language behaviors.

Single doses of benzodiazepine derivatives, such as Tranxene and $\mathrm{Li}$ brium, have been observed to adversely alter cognitive functioning and speech behavior (Gottschalk, 1977). In a double-blind study, several benzodiazepine derivatives were administered to subjects. Five-minute speech samples were collected before and 30-300 min after administration of single doses of chlorodiazapoxide (Librium, $25 \mathrm{mg} /$ orally), Lorazepan ( 3 and $5 \mathrm{mg} \mathrm{i.m.;} \mathrm{and} 2$ and $5 \mathrm{mg}$ i.v.), Triazolam $(0.25-2.0 \mathrm{mg} /$ orally) and Flurazepam ( $30 \mathrm{mg} /$ day/orally, and Lorazepam ( $3 \mathrm{mg} /$ day/orally). An analysis to assess the psychologic and cognitive/intellectual effects of the drug was done before and during treatment. Results indicated that benzodiazepine derivatives (taken in daily therapeutic dosage) had temporary adverse affects on cognitive functioning. Measurements were made of objective content analysis of 5-min speech samples following administration of the drugs. The following speech behaviors were consistently evident: blocking or use of incomplete sentences and phrases; repetition of words in sequence; and inaudible or unintelligible speech. These findings are significant in that they suggest that therapeutic dosages of benzodi- 
azepine derivative drugs may reduce cognitive, intellectual, and speech functioning.

Tricyclics are used widely in the treatment of depression. Side effects commonly reported include dry mouth, tremor, dizziness, tachycardia, blurred vision, and urinary retention. Shatzberg, Cole, and Blumer (1978) suggested that tricyclic drugs also may have an adverse effect on memory and speech production. They reported that patients experienced a halting in normal speech patterns lasting from 1 to $3 \mathrm{sec}$. Tricyclics administered in both therapeutic and large doses (300-400 $\mathrm{mg} /$ day) have been reported to produce dysarthria similar to stuttering (Saunders, 1977; Quader, 1977). Normal speech returned within 2 days after the drug was discontinued.

Chronic usage of some antipsychotic drugs has resulted in the development of tardive dyskinesia, and may produce speech alterations that are characteristic of dysphonia and involve articulation, phonation, resonance, and prosodic components of speech production (Darley, Aronson, and Brown, 1975; Gawel, 1981).

Lithium is a commonly indicated treatment for manic-depressive illness. It is well established that the therapeutic level for Lithium is very close to the level that is toxic. A growing number of reports have described patients who developed severe Lithium neurotoxicity with normal serum Lithium concentration. This phenomenon has been investigated by several researchers (Bond, Carhalho, and Foulks, 1982; Newport and Saunders, 1979; Speir and Hirsh, 1978; West and Meltzer, 1979). Based on their conclusions, some have suggested that increased vulnerability to the occurrence of severe Lithium neurotoxicity may be due to the patient's intense anxiety (West and Meltzer, 1979), preexisting brain damage (Applebaum, Shader, Funkenstein and Henson, 1979), or to changes in RBC Lithium concentration and RBC/plasma Lithium ratio (Elizur, Shipsin, and Gershon, 1972).

Based on a study using psychotic patients, Applebaum et al. (1979) suggested that Lithium toxicity produced ataxia, dysarthria, slurred speech, and progressive onset of confusion. These findings are consistent with other studies that report the occurrence of speech disorders related to Lithium carbonate toxicity at therapeutic levels (Edgell, Peterty, and Pinter, 1970; Melia, 1970; Soloman and Vickers, 1975).

Bond et al. (1982) recently reported a 19-yr-old manic-depressive patient who developed persistent dysarthria with apraxia while receiving a combination of high-dose Haloperidol $(50 \mathrm{mg} /$ day) and Lithium carbonate $(1500 \mathrm{mg} / \mathrm{day})$. After approximately $6 \mathrm{wk}$ of treatment, the patient's speech became slurred and intelligibility decreased. This drug treatment was discontinued after which the patient was given Thordiazine $(100 \mathrm{mg} /$ day, increased to $400 \mathrm{mg} /$ day). The patient's speech became intermittently unintelligible. Thordiazine was discontinued and Chlorpromazine $(600$ $\mathrm{mg} /$ day) was initiated. Even though this dosage was gradually reduced 
over the next 2-wk period, the patient continued to exhibit severe speech difficulties. A speech evaluation conducted at this time indicated that the patient "demonstrated a marked speech problem characterized by reduced intelligibility varying from mildly reduced in single word production to severely reduced in connected speech." Diadochokinetic production was slow, irregular, and slurred. An oral-motor examination indicated deficiencies in lingual elevation, which correlated with the patient's articulation errors and slurred speech. Concurrent with these findings, Spring (1979) reported that a combination of Thoridiazine and Lithium (serum level $0.9 \mathrm{mg} / \mathrm{L}$ ) produced confusion, slurred speech, and affected memory in a $61 \mathrm{yr}$-old manic-depressive patient.

Based on the assumption that anxiety and tension play a central role in precipitating stuttering, pharmaceutical agents (antianxiety and antidepressant drugs) have been indicated in its treatment (Maxwell and Paterson, 1958; Fish and Bowline, 1962; Leanderson ane I evi, 1967). Agents used include Haloperidol, Reserpine, Meprobamate, Chlorpromazine, and Thioridazine. Findings related to the efficacy of such treatment, however, remain varied and inconclusive. Only Haloperidol has been reported to be clinically effective (Quinn and Peachy, 1973; Andrews and Dozsa, 1977). Effectiveness, however, has not been superior to behavior-oriented approaches. Combined with the side effects of Haloperidol, it has not been a preferred method in treating stuttering.

\section{CASE HISTORY}

A case of isolated acquired stuttering following a drug overdose is reported, which differs significantly from previously reported cases. Mr. $\mathrm{H}$. is a 41-yr-old divorced male, formerly employed as a dispatcher for a large industrial manufacturer. He was referred for speech evaluation with severe disfluencies following a (second) suicide attempt. Mr. H. has a history of life crises and has been under psychiatric care since his first suicide attempt (overdose of Talwin) in January 1979. The patient was treated for manic-depression and acute anxiety.

Mr. H. overdosed on Tranxene (and possibly Librium) in January 1982. The patient reported taking $1507.5-\mathrm{mg}$ capsules of Tranxene and a similar amount of Librium. Both Tranxene and Librium have been shown to effect disfluencies in speech (as discussed earlier in this paper). The amounts of each drug taken, as reported by Mr. H., were questioned by the examining medical team due to the alertness of the patient in the emergency room.

Mr. H. remained hospitalized for 2 days. During the course of his stay, frequent reference was made in his medical chart to his slurred speech and disorientation (especially to time). The grasp of the left hand was noted to be weaker than the right. 
The patient was discharged briefly to a mental hospital after which Lithium was prescribed for depression. Four to 5 days following initiation of Lithium, Mr. H. began to experience muscle tightness in his throat and upper chest, resulting in disfluencies in his speech. As previously noted, Lithium has been reported to adversely affect speech, particularly in subjects with preexisting brain damage. The drug was discontinued, but the disfluencies persisted.

Upon evaluation of his communicative disability (April 1982), the patient revealed difficulty retaining information when reading, was unsure of the meaning of some words (he carried a pocket dictionary), and reported word formulation difficulty in speech. These difficulties resolved shortly thereafter.

\section{Initial Characteristics of Disfluencies}

During the initial diagnostic therapy sessions, video and auditory tape recordings were made. From notes of the initial session, it was reported that disfluencies occurred on almost every word. Difficulty managing the breathstream was pronounced; there was a strong breathy component to his vocalizations and puffing of the cheeks. Disfluencies were characterized by prolongations and repetitions of sounds and syllables. The patient's total overall score on the Stuttering Severity Instrument (SSI; Riley, 1980) was 33, ranking him in the 89th percentile and categorizing his stuttering as severe (Table 4). Mr. H. experienced disfluencies on $66 \%$ of words in conversation and an even higher rate in reading aloud (frequency task score, 18). The longest disfluencies lasted approximately 20 sec (duration score, 5). Physical concomitant score was evaluated to be 10 due to the distracting character of his breathiness and head movement and very distracting facial grimacing. Blocking was noted at the laryngeal and labial levels. Eye contact was poor. The patient reported acutc anxiety directly related to his speech and stuttering even when he was alone. Disfluencies diminished somewhat in choral speaking, but rhythm (arm swing, finger tapping) evidenced only a minimal effect. Continuous phon-

Table 4. Riley Scores

\begin{tabular}{lcc}
\hline & \multicolumn{2}{c}{ Scores } \\
\cline { 2 - 3 } \multicolumn{1}{c}{ Date: } & April 1982 & November 1982 \\
\hline Frequency & 18 & 18 \\
Duration & 5 & 3 \\
Concomitants & 10 & 4 \\
Overall & $33^{a}$ & $25^{b}$ \\
\hline
\end{tabular}

" 89 th percentile.

$b 4$ st percentile. 
ation did effect a notable decrease in the severity, but not the frequency of his disfluencies. Because of its impact, it was selected as the technique to be utilized in therapy.

\section{Additional Initial Testing}

Mr. H. was referred for neurologic examination in April 1982. The examination was unremarkable with the exception of his speech. Dysarthria was ruled out. Evidence of organic nervous system disease was not discovered. A CT scan failed to uncover deep white matter lesions. (Normal neurologic and CT scan findings have similarly been revealed in other case reports; Helm et al., 1978; Mazzucchi et al., 1981.)

The Michigan Neuropsychological Test Battery (Smith, 1975) was first administered in May 1982 for purposes of evaluating motor and cognitive functioning, and to compare his performance with neuropsychologic findings from other reported cases of acquired stuttering. The patient's profile indicated organic bilateral cerebral dysfunction with greater involvement of right hemispheric (nonverbal cognitive) then left hemispheric (verbal cognitive) function. Test scores are displayed in Table 5. The Block Design subtest score was particularly depressed relative to other subtests, but fell in the borderline defective range. Depressed Block Design scores were reported by Helm et al. (1978) to be a characteristic feature in acquired stuttering. The patient demonstrated only slight difficulty copying three-dimensional drawings; similarly, repeating rhythmic tapping sequences or melody patterns appeared only mildly affected.

\section{Transitions}

Mr. H. discontinued therapy after a few sessions to enable himself to put other personal matters in order. The patient was reexamined in November 1982, approximately 11 mo following the initial episode. Upon reexamination Mr. H. evidenced some improvements in his speech. The SSI was readministered and categorized $\mathrm{Mr}$. H.'s problem as moderate (score, 25), ranking him in the 41 st percentile (Table 4). The frequency of disfluencies underwent a significant decrease; $48 \%$ in conversation and $38 \%$ in reading. However, because these scores remained in the uppermost category, the frequency task score was unchanged. The duration of his longest blocks diminished to 1 full sec (score, 3). Physical concomitants decreased to 4 as his grimacing and head movements reduced markedly. The breathy, discoordinated phonation lessened but remained noticeable.

The Neuropsychological Battery was readministered in order to evaluate changes in neuropsychologic functioning (Table 5). WAIS-R IQs were significantly lower than those obtained 6 mo earlier, showing declines of 19,12 , and 16 points in verbal, performance, and full scale IQ 
Table 5. Scores on Neuropsychologic Test Battery Measures

\begin{tabular}{|c|c|c|c|}
\hline Neuropsychologic measure & May 1982 & November 1982 & Change \\
\hline Verbal I.Q. & 116 & 97 & -19 \\
\hline Information ${ }^{a}$ & 10 & 8 & -2 \\
\hline Comprehension ${ }^{a}$ & 13 & 10 & -3 \\
\hline Arithmetic ${ }^{\prime \prime}$ & 12 & 8 & -4 \\
\hline Similarities ${ }^{a}$ & 13 & 9 & -4 \\
\hline Vocabulary ${ }^{a}$ & 13 & 12 & -1 \\
\hline Digit $\operatorname{span}^{a}$ & 15 & 10 & -5 \\
\hline Performance I.Q. & 100 & 88 & -12 \\
\hline Digit symbol $^{\alpha}$ & 9 & 7 & -2 \\
\hline Picture completion" & 9 & 9 & 0 \\
\hline Block design" & 7 & 4 & -3 \\
\hline Picture arrangement ${ }^{a}$ & 12 & 9 & -3 \\
\hline Object assembly & 9 & 8 & -1 \\
\hline Full scale I.Q. & 109 & 93 & -16 \\
\hline Peabody Picture Vocabulary Test & 165 & 169 & +4 \\
\hline Hooper Visual Organization Test & 28 & 29 & +1 \\
\hline Ravens Progressive Matrices & 25 & 32 & +7 \\
\hline Benton Visual Rentention Test & 5 & 5 & 0 \\
\hline Benton (errors) & 8 & 3 & \\
\hline Benton Design Copy & 10 & 10 & 0 \\
\hline \multicolumn{4}{|l|}{ Purdue Pegboard } \\
\hline $30^{\prime \prime}$ right & 14 & 18 & +4 \\
\hline $60^{\prime \prime}$ right & 26 & 34 & +8 \\
\hline $30^{\prime \prime}$ left & 14 & 18 & +4 \\
\hline $60^{\prime \prime}$ left & 26 & 31 & +5 \\
\hline $30^{\prime \prime}$ both & 12 & 13 & +1 \\
\hline $60^{\prime \prime}$ both & 23 & 26 & +3 \\
\hline \multicolumn{4}{|l|}{ Smith Symbol Digit Modalities Test } \\
\hline Written & 48 & 50 & +2 \\
\hline Oral & 45 & 51 & +6 \\
\hline Memory for Unrelated Sentences & 26 & 32 & +6 \\
\hline
\end{tabular}

"Scales score.

scores, respectively. Abnormal inter- and intratest scatter was reported. Block Design scores decreased from a scaled score of 7 to 4 (in the 2 nd percentile). The erratic pattern of gains and declines was interpreted to "reflect the persisting effects of brain insult as well as a continuing process of gradual, spontaneous reorganization and recovery of cerebral function." 1

Table 6 compares $\mathrm{Mr}$. H. with the neuropsychologic features reported to be characteristic of acquired stutterers by Helm et al. (1980). The present case strongly evidenced two of the signs (block design and singing), and had a slight impairment in two other areas (drawing three-dimensional figures and tapping patterns), while a fifth feature was not tested.

\footnotetext{
1 A. Smith, test report 1982 .
} 
Table 6. Neuropsychologic Characteristics of Acquired Stuttering

\begin{tabular}{ll}
\hline $\begin{array}{c}\text { The presence of one or more of the following } \\
\text { (Helm, Butler, and Canter, 1980) }\end{array}$ & $\begin{array}{c}\text { Characteristics exhibited by the } \\
\text { present case }\end{array}$ \\
\hline $\begin{array}{l}\text { Difficulty drawing three-dimensional figures both } \\
\text { on command and copying }\end{array}$ & Slight impairment \\
$\begin{array}{l}\text { Difficulty copying block designs; for example, the } \\
\text { Block Design Subtest of the WAIS (Wechsler, }\end{array}$ & Profound impairment \\
1955) & Not tested \\
$\begin{array}{l}\text { Difficulty reproducing and sustaining alternating, } \\
\text { sequential hand positions; for example, those } \\
\text { described by Luria (1968) }\end{array}$ \\
$\begin{array}{l}\text { Difficulty singing melodies } \\
\text { Difficulty reproducing rhythmic tapping patterns }\end{array}$ \\
\hline
\end{tabular}

\section{Masking}

Mr. H.'s speech was examined under a condition of white noise masking to determine if his disfluencies would decrease significantly (as is typical of developmental stutterers). A masking tone was presented binaurally while the subject read from a passage. The masking tone was increased to $95 \mathrm{~dB}$ while the subject read the first 25 words of the passage. After reading 21 words at $95 \mathrm{~dB}$, no further disfluencies were evidenced in the 85 consecutive words that followed, until the intensity level of the masking was diminished. This response was considered to be characteristic of developmental stutterers and dissimilar to reports of acquired stutterers (Shand, 1955; Cherry and Sayers, 1956; Silverman and Goodbar, 1972; Trotter and Silverman, 1973).

\section{Other Phenomena}

Deal (1982) reported a case of stuttering of sudden onset in which the subject experienced disfluencies while miming. Perkins et al. (1976) found conditions that reduced the complexity of speaking, such as whispering, lipping, or miming resulted in significantly fewer (or no) disfluencies. Deal suggested that, for his subject, stuttering while miming might "be a sign of stuttering subsequent to severe psychological pressure" (p. 304). Mr. H. demonstrated no abnormal oral movements when asked to mime a reading passage.

The subject experienced periods of greatly improved fluency. These periods were distinctly related to the consumption of alcohol or use of marijuana. Disfluencies were reduced, but not absent, presumably because of the anxiety-reducing affects of the drugs. 


\section{DISCUSSION}

This patient is unique in that he reveals characteristics of both developmental and acquired stuttering. While the etiology and many clinical features of this case are decidedly those of acquired stuttering, the patient exhibits many characteristics of developmental stuttering concomitantly. Table 7 contrasts selected characteristics associated with different types of stuttering and reveals features of both developmental and acquired stuttering that the present case evidenced. Mr. H.'s similarities to developmental stuttering included anxiety related to speaking, secondary characteristics associated with stuttering, improvement in choral reading, and masking. Like acquired stutterers, the present case evidenced no adaptation effect, had disfluencies in all word positions and on small grammatic words, as well as substantive words.

Interestingly, the symptoms manifested by the patient that were similar to developmental stuttering could each be related to anxiety, reactions to his own speech, or alterations in his ability to monitor his own speech, all of which can be associated with psychoperceptual attributes of spcaking and self-monitoring. Because of this and the patient's psychiatric history, it was necessary to attempt to rule out psychogenesis as an etiology of the disorder. Helm et al. (1980) discuss psychogenic acquired stuttering as a clinical entity; they report symptomotology to include failure to exhibit neuropsychologic or clinical anatomical abnormalities and variability in the occurrence of disfluencies, related to anxiety attacks. On these bases, the present case failed to fall within the definition.

However, the strong psychiatric component should not be easily discounted. Comparisons with neuropsychologic testing data from other studies also found the patient to differ from previously reported group data. Cox (1982) compared adult (developmental) stutterers with brain damaged and non-brain damaged adult psychotic patients on their neuropsychologic performances. When compared with the three groups, $\mathrm{Mr}$. $\mathrm{H}$. was most similar to the brain damaged psychotic patients (Table 8). The comparison is somewhat limited in that only the WAIS scores could be contrasted, because of differences in the neuropsychologic test batteries. Even on this limited basis, however, Mr. H.'s performance on the Block Design subtest (a distinctive feature of acquired stuttering) was markedly different. Mr. H. also demonstrated more intersubtest scatter, ranging from a low of 4 to a high of 12. Cox's grouped subjects ranged from a low of 7.80 to a high of 10.91 .

Other observations in the literature also tend to diminish the suspicion of a psychogenic origin in the present case. Deal $(1982$, p. 304) reports eight features that may be characteristic of stuttering subsequent to psychologic trauma: 

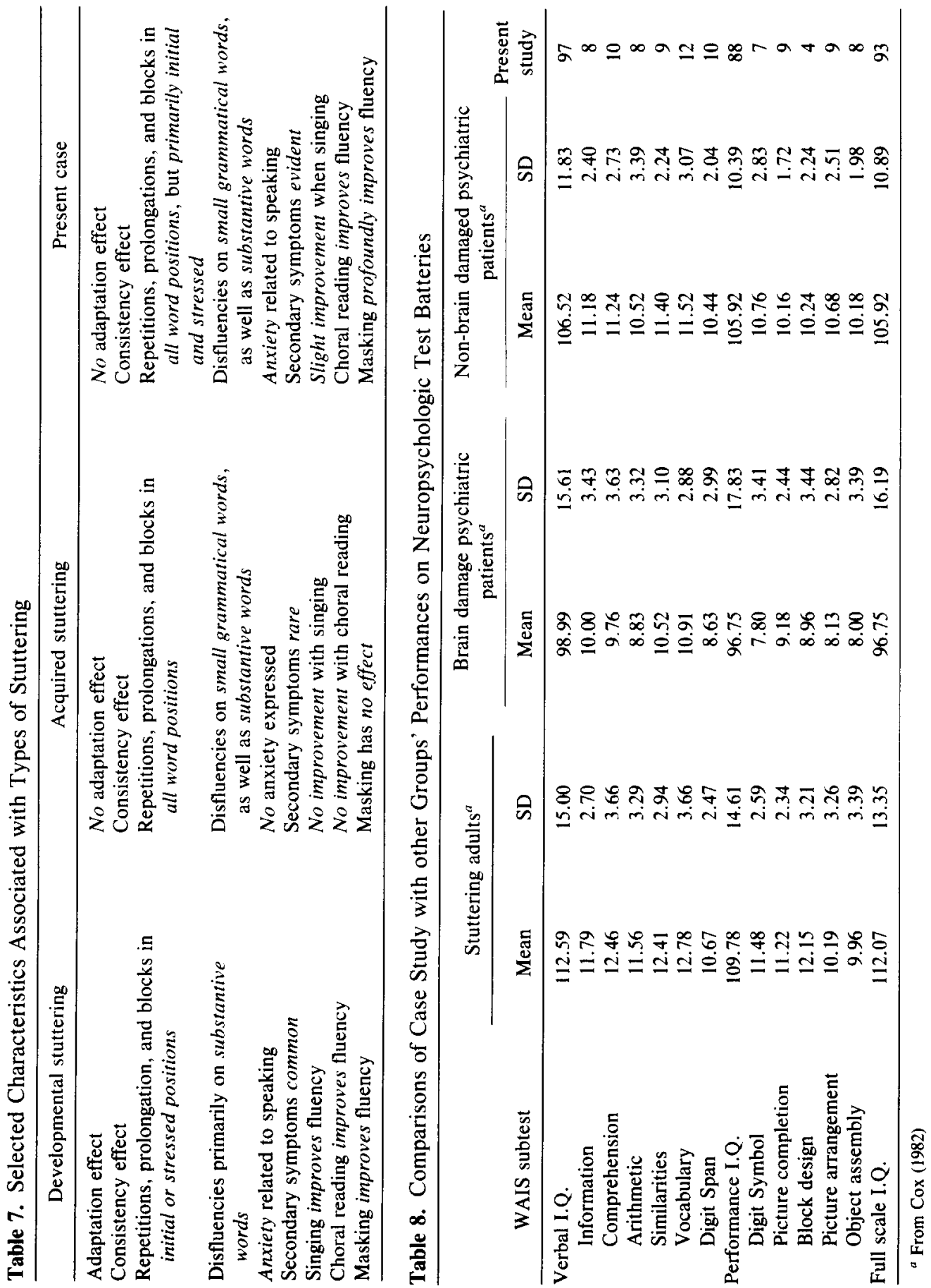
1) The onset of stuttering is sudden.

2) The onset is temporally related to a significant event ... which seemed to reflect extreme psychological pressure.

3) The pattern was primarily repetition of initial or stressed syllables.

4) The pattern was affected little by choral reading, white noise, initial trial of delayed auditory feedback, singing and different communicative situations.

5) Initially, the patient had no islands of fluency; even automatic, overlearned social responses were stuttered.

6) Initially, the patient did not express any interest in his stuttering.

7) The patient did not exhibit secondary symptoms ... did not avoid sounds, words, or speaking situations. He appeared to make no attempt to inhibit his stuttering in any discernible way. . .

$8)$... he evidenced the same patterns of repetitions during mimed reading aloud which is not common with developmental stuttering or associated with stuttering secondary to brain damage.

Additionally, Deal's patient was reported to have been fluent when speaking to other patients, but nonfluent when speaking to staff members.

While our patient exhibited many of these features, in particular 1-3, marked differences can be noted on several parameters. For example, the profound affect of masking, the persistent concern regarding his speech, the presence of secondary symptoms, and his failure to demonstrate disfluencies (repetitions) during mimed reading.

The patient differed from children with developmental stuttering, as well. Comparison with scores of 26 stuttering children on the Michigan Neuropsychological Test Battery (Rentschler and Liebetrau, 1981) revealed dissimilarities that were not unlike those seen in comparisons with Cox's (1982) developmental stutterers. While neuropsychologic deficits are reported in some stuttering children (Liebetrau and Daly, 1981; Rentschler and Liebetrau, 1981), the nature and form of their deficits differ from this case of acquired stuttering.

Several aspects of Mr. H.'s behaviors were characteristic of developmental stuttering, for example the profound effect of masking and the dramatic reduction of stuttering evidenced under conditions of perceptualaltering drugs. These effects have not been observed to be characteristic in other cases of acquired stuttering, but are commonly reported among developmental stutterers.

Two alternatives that attempt to explain the patient's mix of developmental and acquired stuttering characteristics are hypothesized. One explanation suggests that there is a strong psychologic overlay to this fluency problem, which accounts for the secondaries, anxiety related to speaking and the fluency effecting results of reducing those anxieties. This explanation, however, fails to account for the neuropsychologic impairments and other symptoms of acquired stuttering. A second alternative 
relates more directly to a relationship between organic dysfunction and developmental stuttering. This explanation posits that this case may represent a link associating some forms of developmental stuttering with demonstrable organic dysfunction. In that the patient demonstrates signs of organicity and symptoms of developmental stuttering, it would seem possible that similar organic dysfunctions may be at the root of some developmental stuttering, as well. Cox (1982) pointed out that his adult developmental stutterers were unimpaired in their neuropsychologic performance, while younger (adolescent) samples of stutterers revealed varying degrees of impairment. This may suggest that the developmental stutterer may encounter subtle dysfunctions resulting, for example, in auditory imperception (Rentschler and Liebetrau, 1981), which serves to effect disfluency. Either the subtlety, the developmental nature of the dysfunction, or our difficulty in measuring it, may serve to mask it. That is to say, the developmental stutterer may learn to be able to compensate (in part) for the dysfunction or that the subtlety of the dysfunction may conceal it from our as yet imprecise assessment instruments.

Carrying this hypothesis further, this case may then represent a link between organic dysfunction and some forms of developmental stuttering. Others have reported the likelihood of subtypes of developmental stutterers and the impact that failing to account for subtypes may have on research findings (Rentschler, in press). Thus, at least one subtype may be directly related to organic dysfunction.

\section{REFERENCES}

Andrews, G. and Dozsa, M. Haloperidol and the treatment of stuttering. Journal of Fluency Disorders, 1977, 2, 214-224.

Andrews, G., Quinn, P.T., and Sorby, W.A. Stuttering: An investigation into cerebral dominance. Journal of Neurology, Neurosurgery \& Psychiatry, 1972, $35,414-418$.

Applebaum, P.S., Shader, S.F., Funkenstein, H.H., and Hanson, M.A. Difficulties in the clinical diagnosis of lithium toxicity. American Journal of Psychiatry, 1979, 136, 1212-1213.

Arend, R., Handzel, L., and Weiss, B. Dysphatic stuttering. Folia Phoniatrica, $1962,14,55-56$.

Bloodstein, O. A Handbook on Stuttering, 3rd ed. Chicago: National Easter Seal Society, 1981.

Bond, W.S., Carhalho, M., and Foulks, E.F. Persistent dysarthria with apraxia associated with a combination of lithium carbonate and haloperidol. Journal of Clinical Psychiatry, 1982, 43, 256-257.

Borkowski, J.G., Benton, A.L., and Spreen, O. Word fluency and brain damage. Neuropsychologia, 1967, 5, 135-140. 
Canter, G.J. Observations on neurogenic stuttering: A contribution to differential diagnosis. British Journal of Disorders of Communication, 1971, 6, 139-143.

Caplan, L. An investigation of some aspects of stuttering-like speech in adult dysphasic subjects. Journal of the South African Speech-Hearing Association, $1972,19,52-66$.

Cherry, C. and Sayers, B.M. Experiments upon the total inhibition of stammering by external control and some clinical results. Journal of Psychosomatic Research, 1956, I, 233-246.

Cox, M.D. The stutterer and stuttering: Neuropsychological correlates. Journal of Fluency Disorders, 1982, 7, 129-140.

Darby, J.K. The interaction between speech and disease. In: Speech Evaluation in Medicine, J.K. Darby (ed.). New York: Grune and Stratton, 1981.

Darley, F., Aronson, A., and Brown, J. Motor Speech Disorders. W. B. Saunders, 1975.

Deal, J.L. Sudden onset of stuttering: A case report. JOurnal of Speech and Hearing Disorders, 1982, 47, 301-304.

Donnan, G.A. Stuttering as a manifestation of stroke. Medical Journal of Australia, 1979, 1, 44-45.

Edgell, P.G., Peterty, G., and Pinter, E.J. Lithium toxicity. Lancet. 1970, i, 415416.

Elizur, A., Shopsin, B., and Gershon, S. Intracellular lithium ratios and clinical course in affective states. Clinical Pharmacology Therapy, 1972, 13, 947-952.

Farmer, A. Stuttering repetitions in aphasic and nonaphasic brain damaged adults. Cortex, 1975, 11, 391-396.

Fish, C.H. and Bowling, E. Effect of amphetamines on speech defects in the mentally retarded. California Medicine, 1962, 96, 109-111.

Gawel, M.J. The effects of various drugs on speech. British Journal of Disorders of Communication, 1981, 16, 51-57.

Gottschalk, L.A. Effects of certain benzodiazepine derivatives on disorganization of thought as manifested in speech. Current Therapeutic Research, 1977, 21. 192-201.

Gregory, H.H. and Hill, D. Stuttering therapy for children. In: Seminars in Speech, Language and Hearing, Perkins, W. (ed.). New York: Thieme-Stratton, 1980.

Helm, N., Butler, R., and Benson, D.F. Acquired stuttering. Neurology, 1978, $28,1159-1165$.

Helm, N., Butler, R., and Canter, G.J. Neurogenic acquired stuttering. Journal of Fluency Disorders, 1980, 5, 269-279.

Inglis, A.L. Neurological stammer-A case study. Australian Journal of Human Communication Disorders, 1979, 7, 1.

Jones, R.K. Observations on stammering after localized cerebral injury. Journal of Neurology, Neurosurgery and Psychiatry, 1966, 29, 192-195. 
Leanderson, R. and Levi, L. A new approach to the experimental study of stuttering and stress. Acta Oto-Laryngol. (suppl.) 1967, 224, 311-316.

Liebetrau, R.M. and Daly, D.A. Auditory processing and perceptual abilities of "organic" and "functional" stutterers. Journal of Fluency Disorders, 1981, 6, 219-231.

Maxwell, R.D.H. and Paterson, J.W. Meprobamate in the treatment of stuttering. British Medical Journal, 1958, 5075, 873-874.

Mazzucchi, A., Moretti, G., Carpeggiani, P., and Parma, M. Clinical observations on acquired stuttering. British Journal of Disorders of Communication, 1981, $16,1$.

Melia, P.I. Prophylactic lithium in recurrent effective disorders. Journal Irish Medical Association, 1970, 63, 353-357.

Newport, P.K. and Saunders, M. Lithium neurotoxicity. Post-Graduate Medical Journal, 1979, 55, 701-703.

Perkins, W., Rudas, J., Johnson, L., and Bell, J. Stuttering: Discourdination of phonation with articulation and respiration. Journal of Speech and Hearing Research, 1976, 19, 509-522.

Quader, S. Dysarthria: An unusual side effect of tricyclic antidepressants. British Medical Journal, 1977, 2, 97.

Quinn, P. and Andrews, G. Neurological stuttering-A clinical entity? Journal of Neurology, Neurosurgery, and Psychiatry, 1977, 40, 699-701.

Quinn, P. and Peachy, C. Haloperidol in the treatment of stuttering. British Journal of Psychiatry, 1973, 123, 247.

Rentschler, G.J. Effects of subgrouping in stuttering research. Journal of Fluency Disorders (in press).

Rentschler, G.J, and Liebetrau, R.M. Dichotic listening abnormalities in stuttering children. (Paper presented at annual conference of American SpeechLanguage-Hearing Association, Los Angeles, 1981.)

Riley, G.D. Stuttering Severity Instrument. Tigard, OR: C.C. Publications, 1980.

Riley, G. and Riley, J. Motoric and linguistic variables among children who stutter: A factor analysis. Journal of Speech and Hearing Disorders, 1980, 45, $504-$ 514.

Rosenbek, J., Messert, B., Collins, M., and Wertz, R.T. Stuttering following brain damage. Brain and Language, 1978, 6, 82-86.

Rosenfield, D.B. Stuttering and cerebral ischemia. New England Journal of Medicine, 1972, 287, 991.

Rosenfield, D.B., Miller, S., and Feltovich, M. Brain damage causing stuttering. Transactions of the American Neurology Association, 1980, 105, 187-188.

Saunders, M. Dysarthria with tricyclic antidepressants. British Medical Journal, July $30,1977,317$.

Shane, M.L.S. Effect on stuttering of alteration in auditory feedback. In: Stuttering in Children and Adults, Johnson, W. (ed.). Minneapolis: University of Minnesota Press, 1955. 
Shatzberg, A.F., Cole, J.O., and Blumer, D.P. Speech Blockage: A tricyclic side effect. American Journal of Psychiatry, 1978, 135, 5, 600-601.

Silverman, F.H. and Goodbarr, M.T. The effect of auditory masking on the fluency of normal speakers. Journal of Speech and Hearing Research, 1972. $15,543-546$.

Smith, A. Neuropsychological testing in neurological disorders. In: Advances in Neurology, Friedlander, W.J. (ed.). 7, New York: Raven Press, 1975.

Soloman, K. and Vickers, R. Dysarthria resulting from lithium carbonate. Journal of the American Medical Association, 1975, 213, 280.

Speir, J. and Hirsh, S.R. Severe lithium toxicity with normal serum concentrations. British Medical Journal, 1978, 1, 815-816.

Spring, G.K. Neurotoxicity with combined use of lithium and thioridazine. Journal of Clinical Psychiatry, 1979, 40, 135-138.

Trotter, W.D. and Silverman, F.H. Experiments with the stutter-aid. Perceptual Motor Skills, 1973, 36, 1129-1130.

VanRiper, C. The nature of stuttering. Englewood Cliffs, NJ: Prentice-Hall, 1971.

West, A.P. and Meltzer, H.Y. Paradoxical lithium neurotoxicity: A report of five cases and a hypothesis about risk for neurotoxicity. American Journal of Psychiatry, 1979, 136, 963-966. 